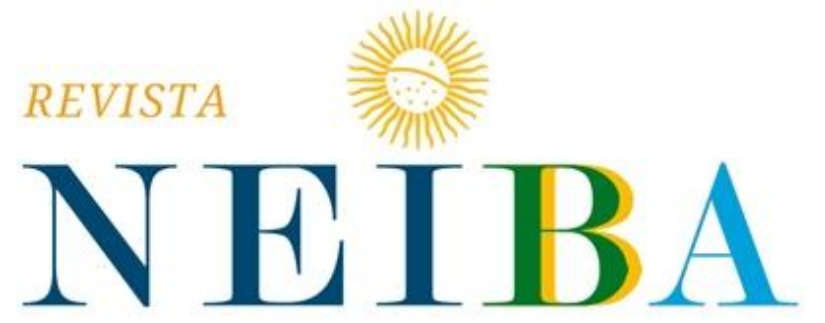

CADERNOS ARGENTINA-BRASIL
Volume 9, 2020, p. 01-22

DOI: $10.12957 /$ neiba.2020.50950 | e50950 IISSN: 2317-3459

\title{
O ACORDO DE ASSOCIAÇÃO MERCOSUL-UNIÃO EUROPEIA E A POLITIICA EXTERNA BRASILEIRA
}

THE EU-MERCOSUR ASSOCIATION AGREEMENT AND BRAZILIAN FOREIGN POLICY

\section{Vitória Totti Salgado ${ }^{1}$}

\section{Regiane Nitsch Bressan ${ }^{2}$}

${ }^{1}$ Programa de Pós-Graduação em Relações Internacionais 'San Tiago Dantas' (UNESP, UNICAMP, PUC-SP), São Paulo, SP, Brasil. E-mail: vitoria.totti@unesp.br. ORCID: https://orcid.org/0000-0002-4059-9711.

${ }^{2}$ Universidade Federal de São Paulo (UNIFESP), Escola Paulista de Política, Economia e Negócios (EPPEN), Osasco, SP, Brasil. Programa de Pós-Graduação em Relações Internacionais 'San Tiago Dantas' (UNESP, UNICAMP, PUC-SP), São Paulo, SP, Brasil. Email: regiane.bressan@unifesp.br. ORCID: https://orcid.org/0000-0002-7101-793X

Recebido em: 01/01/2020 | Aceito em: 27/04/2020. 


\section{RESUMO}

O objetivo do artigo é analisar as negociações do Acordo de Associação entre Mercosul e União Europeia a partir da política externa brasileira. Após 20 anos de negociações, entre avanços e retrocessos, o Acordo entre os blocos regionais foi firmado em julho de 2019. O trabalho busca desvelar e entender as implicações políticas brasileiras para a conclusão do acordo, perpassando os governos Lula (2003-2010), Dilma (2011-2016), Temer (2016-2018) e Bolsonaro (2019-atual). Conclui-se que a mudança dos governos nos países do Mercosul, sobretudo no Brasil, reorientou a postura do bloco nas negociações do Acordo de Associação Mercosul-União Europeia. A ascensão da direita no governo brasileiro e a mudança nas diretrizes de política externa para a liberalização econômica e o realinhamento com as grandes potências ocidentais, determinaram o posicionamento do Brasil frente às negociações dentre o Mercosul e com a União Europeia, as quais culminaram na conclusão do acordo histórico.

Palavras-chave: Política Externa Brasileira; Acordo de Associação Mercosul-União Europeia; Integração Econômica Regional.

\section{ABSTRACT}

The purpose of the article is to analyze the negotiations on the Association Agreement between Mercosur and the European Union based on Brazilian foreign policy. After 20 years of negotiations, between advances and setbacks, the Agreement between the regional blocs was signed in July 2019. The work seeks to unveil and understand the Brazilian political implications for the conclusion of the agreement, spanning the Lula governments (2003-2010), Dilma (2011-2016), Temer (2016-2018) and Bolsonaro (2019-current). It is concluded that the change of governments in the Mercosur countries, especially in Brazil, reoriented the bloc's stance in the negotiations for the Mercosur-European Union Association Agreement. The rise of the right in the Brazilian government and the change in foreign policy guidelines for economic liberalization and realignment with the great western powers, determined Brazil's position in the face of negotiations between Mercosur and the European Union, which culminated in the conclusion of the historic agreement.

Keywords: Brazilian foreign policy; Mercosur-European Union Association Agreement; Regional Economic Integration. 


\section{INTRODUÇÃO}

No dia 28 de junho de 2019, após duas décadas de negociações, concluiu-se a parte comercial do Acordo de Associação entre Mercosul e União Europeia (UE). A conclusão do acordo depois de um longo e conturbado período de negociações traz o amplo questionamento: O que mudou? Considerando que toda formulação de política externa se configura como uma tentativa de compatibilizar o quadro interno de um país com o contexto externo, ou seja, as necessidades domésticas com as possibilidades internacionais, questiona-se quais foram as mudanças na política externa brasileira que fizeram com que o acordo fosse concluído. Nesse sentido, o artigo tem como objetivo analisar as negociações do acordo do ponto de vista da política externa brasileira, além das implicações gerais dos relacionamentos do Brasil com o Mercosul e com a União Europeia para o acordo. Propõe-se análise histórica das diretrizes e ações de política externa de 2003 a 2019, com foco na integração regional do Mercosul, na agenda comercial, e no relacionamento com a União Europeia, perpassando os governos Lula (2003-2010), Dilma (2011-2016), Temer (2016-2018), e o atual governo Bolsonaro.

O ponto de partida para a análise será a política externa brasileira, e como o Brasil desempenhou papel-chave para a conclusão do acordo. Portanto, não se pretende realizar análise exaustiva do acordo, de seus possíveis impactos econômicos ou do processo de implementação do mesmo. O artigo encontra-se dividido em 6 seções, para além desta introdução. A primeira seção aborda o Acordo Mercosul-UE de maneira geral e o desenrolar das negociações desde a perspectiva brasileira. Logo, uma seção para cada governo abordado: Lula, Dilma, Temer e Bolsonaro. Em uma seção para considerações finais, apresenta-se breves ponderações acerca dos impactos das mudanças de política externa brasileira para a conclusão do acordo.

\section{ACORDO DE ASSOCIAÇÃO MERCOSUL-UNIÃO EUROPEIA}

Em junho de 2019, concluiu-se a parte comercial do Acordo de Associação entre Mercosul e União Europeia (UE). De início, é necessário aclarar que o Acordo de Associação não produz efeitos imediatos, uma vez que ainda não foi assinado formalmente um tratado e que, atualmente, está a se realizar uma revisão técnica e jurídica do acordo, além da tradução do texto nos 23 idiomas oficiais dos blocos. 
Portanto, intentar-se-á examinar, sinteticamente, os pontos positivos e negativos do acordo para ambas as partes com base nas informações divulgadas até o presente momento. Ademais, analisar-se-á as rodadas de negociação do ponto de vista da política externa brasileira, e quais as implicações gerais dos relacionamentos do Brasil com o Mercosul e com a União Europeia para o acordo.

O Acordo de Associação UE-Mercosul representa, antes de tudo, a reafirmação da importância da liberalização econômica regional e inter-regional como forma de impulsionar a liberalização econômica mundial, em um momento em que o cenário internacional está marcado por uma onda de protecionismos, principalmente após a eleição de Donald Trump, nos Estados Unidos. Para o Mercosul, o acordo revigora a relevância do bloco na comunidade internacional como capaz de promover e representar os países do Cone Sul. Além de que, visto a crise do regionalismo sulamericano e do Mercosul particularmente, o acordo concede uma "sobrevida" ao bloco, estimulando, assim, a sua revisão e atualização. Para a UE o acordo birregional é expressão do inter-regionalismo, um conceito que tem sido uma das principais modalidades de política externa do bloco, como forma de projetar o seu próprio modelo de integração (Sanahuja; Rodríguez, 2019).

Quanto às expectativas econômicas do acordo, o Mercosul e a UE representam, juntos, um PIB de cerca de 20 trilhões de dólares, aproximadamente $25 \%$ da econômica mundial, e mercado de 780 milhões de pessoas (Brasil, 2019). A UE é o segundo parceiro comercial do Mercosul e o primeiro em matéria de investimentos, e o Mercosul é o oitavo parceiro comercial extrarregional da UE. Em 2018, a corrente de comércio birregional entre os blocos foi de mais de 90 bilhões de dólares. O Mercosul aceitou liberalizar 91\% das importações provenientes da UE, em um período de desgravação de até 15 anos, e a UE irá liberalizar 95\%, em um período de até 10 anos (Brasil, 2019). O acordo será uma das maiores áreas de livre-comércio do mundo, e abrange tanto temas tarifários quanto de natureza regulatória, como serviços, compras governamentais, facilitação de comércio, barreiras técnicas, medidas sanitárias e fitossanitárias, e propriedade intelectual. A despeito dos impactos econômicos e comerciais do acordo, o longo período de negociação revela a dificuldade em se atingir 
consenso quanto aos seus termos, tanto dentre os países do Mercosul, como entre e o Mercosul e a UE.

Divide-se as negociações do acordo, grosso modo, em três fases: de 1999 a 2004, de 2010 a 2012, e de 2016 a 2019, que culminou na sua conclusão. Na primeira fase, foram elaborados textos negociadores e troca de ofertas de compromissos tarifários, consideradas insatisfatórias por ambas as partes. Tal insatisfação refere-se ao protecionismo do setor agrícola por parte da UE, ilustrado, por exemplo, nos altos subsídios fornecidos pela UE aos Estados-membros por meio da Política Agrícola Comum (PAC), e à relutância mercosulina em liberalizar o setor manufatureiro, de serviços e as compras públicas, em especial por parte do Brasil. A proposta apresentada pela UE em 2001 estava muito aquém das ambições dos países do Mercosul, uma vez que se limitou a oferecer cotas tarifárias preferenciais para os produtos mais sensíveis da PAC, como carne bovina, açúcar e laticínios, produtos cujo mercado é altamente competitivo nos países sul-americanos (Sanahuja; Rodríguez, 2019).

De acordo com Pennaforte, Ribeiro e Bones (2018), a falta de coesão interna do Mercosul dificultou a convergência de interesses e de uma proposta comum nesta primeira fase de negociações. Dentre as razões que elucidam esta dificuldade, pode-se mencionar a crise do Mercosul em função da desvalorização unilateral da moeda brasileira e os efeitos negativos dessa medida sobre a economia argentina, a crise econômica brasileira (1998) e argentina (2001), as divergências entre Brasil e Argentina quanto ao ritmo de aprofundamento da integração regional, e o ajuste de prioridades na política externa brasileira em direção à cooperação Sul-Sul (Saraiva, 2009). Não obstante, a chamada "onda rosa" na América Latina conferiu aos países relativa convergência político-ideológica, o que direcionou os projetos de integração regional para a concertação política e a mediação de crises intrarregionais. No que diz respeito ao Mercosul, apesar das dificuldades na dimensão comercial, o bloco experimentou uma redefinição de seu perfil de acordo com o paradigma do regionalismo pós-liberal, no sentido de direcionar o projeto de integração para além da esfera econômica, abrangendo questões políticas, sociais e culturais. 
Durante o período de seis anos de estagnação das negociações (2004-2010), o panorama político e econômico mundial sofreu mudanças dramáticas, a começar pela paralisação da Rodada Doha e a crise econômica de 2008. O estancamento no âmbito multilateral prejudicou o progresso nas negociações entre Mercosul e UE ao mesmo tempo que propiciou incentivos à proliferação de acordos bilaterais (Menezes; Paiva, 2019). Nesse período, a União Europeia e o Brasil assinaram, em 2007, uma Parceria Estratégica, de cunho majoritariamente político e cultural. A parceria visava o reforço ao multilateralismo e a busca de ações conjuntas em temas de energia, direitos humanos, pobreza, questões ambientais, estabilidade na América Latina, e o retorno das negociações com o Mercosul. No entanto, a aproximação entre União Europeia e Brasil não resultou na retomada das negociações, além de ter causado estranheza nos outros países membros do Mercosul (Hoffmann, 2009).

A segunda fase de negociações foi oficialmente proclamada em maio de 2010, na cúpula de Madri. Seguida dos efeitos da crise mundial de 2008 - que passou a afetar também os países em desenvolvimento provocando o fim do boom das commodities a reaproximação dos dois blocos tornou-se estratégica com vistas a superar a crise por meio da liberalização de novos mercados para seus produtos (Pennaforte; Ribeiro; Bones, 2018). No entanto, a União Europeia não fez concessões significativas quanto ao setor agrícola e, além disso, a crise da dívida pública da Zona do Euro desviou a atenção da Europa para o âmbito interno do bloco, que passou a aplicar medidas de austeridade econômica para os países membros. No Cone Sul, a reeleição da presidente Cristina Kirchner em 2010, na Argentina, foi também identificada como uma das principais causas para a estagnação das negociações, devido ao seu posicionamento nacionalprotecionista (Mariano, 2019). Apesar das tentativas brasileiras no governo Dilma de levar adiante as negociações, os mesmos entraves de 2004 foram encontrados, e as negociações voltaram à paralisia.

Em maio de 2016, Mercosul e a União Europeia intercambiaram ofertas de acesso aos mercados de bens, serviços e compras governamentais, reativando novamente as negociações, agora em sua terceira fase. Segundo Zelicovich (2019), o relançamento das negociações deve ser entendido como resposta às transformações do sistema 
internacional decorrente da crise da globalização e da ordem liberal internacional. Ademais, Sanahuja e Rodríguez (2019) consideram a crise da globalização como a principal razão da alteração de expectativas e do cálculo estratégico dos dois blocos em relação ao acordo.

Além disso, o relançamento deve-se, em larga medida, à ascensão de novos governos de viés mais liberal na Argentina, com a eleição de Maurício Macri em 2015, e no Brasil, com o impeachment da presidente Dilma Rousseff em 2016 e a conseguinte ascensão de Michel Temer à presidência. Temer e Macri alinharam-se e declararam o acordo com a União Europeia ao nível de prioridade para o Mercosul. Não obstante, cabe ressaltar a tentativa de impulsionar o acordo pela presidente Dilma, em 2013, decorrente de pressões e críticas de entidades empresariais devido à falta de mudanças na política comercial do país (Menezes; Paiva, 2019).

Visto a conclusão das negociações em 2019, nas próximas seções será realizada análise da política externa brasileira dos governos Lula, Dilma, Temer e Bolsonaro, com vistas a elucidar os interesses brasileiros no acordo e a relação do Brasil com o Mercosul e com a União Europeia, de 2003 a 2019. Objetiva-se localizar os momentos de inflexão da política externa brasileira referente aos interesses no Acordo de Associação Mercosul-União Europeia que culminaram na sua conclusão em 2019.

\section{GOVERNO LULA (2003-2010)}

Optou-se por iniciar a análise de política externa em relação ao Mercosul e à União Europeia pelo Governo Lula (2003-2010) uma vez que este engloba o período mais longo de paralisia das negociações. Intenta-se identificar as razões desta estagnação a partir da perspectiva brasileira, e averiguar os interesses brasileiros em assinar uma Parceria Estratégica com a União Europeia, em 2007, à parte do Mercosul.

O governo Lula, e os anos 2000 de maneira geral, foram marcados por um contexto internacional favorável para a ascensão do Brasil enquanto potência emergente. O boom das commodities promoveu o crescimento econômico; o relativo afastamento da

influência estadunidense devido à incansável "guerra ao terror" concedeu maior margem de manobra para o Brasil no hemisfério; e a convergência político-ideológica decorrente da "onda rosa" na América Latina fortaleceu os projetos de integração 
regional. De acordo com Ricupero (2017), a política externa do governo Lula desdobrouse ao longo de quatro eixos principais: (i) a busca pelo reconhecimento do Brasil como ator político global de primeira ordem; (ii) a consolidação de condições econômicas internacionais que favorecessem o desenvolvimento a partir das vantagens comparativas do Brasil, concentradas na agricultura; (iii) a ênfase na cooperação Sul-Sul; e (iv) a edificação de espaço político-estratégico e econômico-comercial exclusivamente sul-americano a partir da expansão gradual do Mercosul.

Nesse sentido, a América do Sul continuou a ocupar posição prioritária para a política externa brasileira, aprofundando o comportamento seguido no governo anterior, de Fernando Henrique Cardoso. A diplomacia do presidente Lula soube se valer das afinidades político-ideológicas entre os líderes de importantes países da região, como Argentina e Venezuela, para fazer avançar o projeto de integração regional sob a liderança brasileira. Destarte, a diplomacia brasileira procurou articular um projeto de construção de uma liderança regional articulada às perspectivas de desenvolvimento nacional e à ascensão do país para a posição de potência global (Saraiva, 2009).

Em relação às negociações entre Mercosul e União Europeia, a troca de propostas em 2004 entre as partes provou-se infrutífera devido à inflexibilidade da União Europeia em conceder a abertura do seu mercado para produtos do setor agropecuário mercosulino, e à igual inflexibilidade dos países do Mercosul de liberalizar o setor manufatureiro, o comércio de serviços e abrir as licitações públicas para as firmas europeias. A primeira fase de negociações, vale ressaltar, esteve condicionada às negociações da Rodada Doha, nos marcos da Organização Mundial do Comércio (OMC). No que toca ao Brasil, o seu protagonismo nas negociações agrícolas da Rodada Doha está intrinsecamente associado às reivindicações do Mercosul em relação à liberalização do comércio com a UE.

Não obstante, a projeção internacional do Brasil nesse período e a sua vinculação à importantes fóruns de diálogos entre países emergentes como o IBAS (Índia, Brasil e África do Sul) e os BRICS (Brasil, Rússia, Índia, China e África do Sul), elevou a importância do diálogo com o Brasil para as grandes potências. Nesse contexto, a União 
Europeia propôs ao Brasil um acordo de Parceria Estratégica, de forma paralela ao mecanismo de diálogo político já consolidado com o Mercosul. Nas palavras de Saraiva (2009, p. 89), “o Brasil seria visto como 'líder natural da América do Sul', motor do Mercosul e capaz de frear os movimentos da Venezuela de Chávez e contribuir para maior estabilidade na América do Sul". Desde a perspectiva brasileira, a aproximação com países europeus representava um movimento estratégico para balancear o unilateralismo hegemônico dos Estados Unidos.

Nota-se que o posicionamento do país na América do Sul e no cenário internacional devem ser entendidos à luz de dois fatores constitutivos da política externa brasileira, enraizados na sociedade e no Estado: a autonomia e o universalismo (Vigevani et. al, 2008). De igual modo, o relacionamento do Brasil com a União Europeia esteve condicionado por sua relação com os países do Mercosul, e vice-versa. Nesse sentido, entende-se que a concomitância do período de paralisia nas negociações do Acordo de Associação Mercosul-UE e a assinatura da Parceira Estratégica Brasil-UE representam um cálculo estratégico coerente com as diretrizes de política externa seguidas no governo Lula. Com o fortalecimento da presença brasileira na política internacional e o aprofundamento do processo de integração regional no âmbito do Mercosul, o Brasil possuía maior poder de barganha para com a União Europeia nas negociações de livrecomércio. Além disso, o boom das commodities e o aumento do fluxo de comércio com a China propiciou ao Brasil crescimento econômico e a possibilidade de negar-se a concluir o Acordo de Associação caso a UE não fizesse as concessões quanto à liberalização do setor agrícola. Ademais, as exportações do Brasil para o Mercosul também cresceram no período, impulsionando o setor manufatureiro, que seria um dos pontos de exigência de liberalização por parte da UE. Garantir a liderança brasileira na integração regional atendia uma das prioridades da política externa do governo Lula, e a proteção do setor manufatureiro constituía fator essencial para atingir esse objetivo.

Não obstante, a atuação do Brasil na cena internacional implicava na aproximação com as grandes potências, seguindo a lógica do universalismo. A Parceria Estratégica com a UE, portanto, servia aos interesses brasileiros no sentido de estabelecer uma aproximação política que, em alguma medida, balanceava a hegemonia estadunidense 
nas organizações internacionais. Por fim, em maio de 2010, seriam formalmente retomadas as negociações do Acordo de Associação na cúpula de Madri, já sob os efeitos da crise de 2008, o que reaproximou os dois blocos devido a necessidade de superar a crise por meio da liberalização de novos mercados.

\section{GOVERNO DILMA (2011-2016)}

O governo de Dilma Rousseff herdou de seu antecessor as mesmas diretrizes de política externa. Segundo Cornetet (2014, p. 111), foram mantidos os mesmos objetivos, "incluindo a obtenção de desenvolvimento por meio da diversificação de parceiros e a afirmação do Brasil como líder regional". Ademais, o Brasil seguiu atuando como representante dos países do Sul em fóruns multilaterais, e na defesa de um multilateralismo apoiado na ideia de revisar as organizações internacionais (Saraiva; Gomes, 2016). No entanto, a política externa do governo Dilma diminuiu os esforços para o alcance destes objetivos, além de contar com maiores limitações na esfera internacional. À essa diminuição de esforços, Cornetet (2014) aponta dois motivos: (i) o perfil administrativo da presidente Dilma, e (ii) as mudanças na conjuntura internacional, marcada por uma crise econômica persistente e por instabilidade política em algumas regiões.

Na esfera regional, o Mercosul continuou a ocupar lugar relevante na política externa brasileira para a administração das relações do Brasil com os países do bloco, em especial com a Argentina. Em 2012, o Mercosul atravessou um período turbulento devido à suspensão temporária do Paraguai devido ao impeachment do presidente Fernando Lugo, seguida da adesão da Venezuela como membro pleno ao bloco. Ainda, a ascensão da presidente Dilma esvaziou a dimensão política da atuação brasileira frente à região (Saraiva; Gomes, 2016). No caso da crise política na Venezuela, o Mercosul ficou paralisado e os intentos de solução da crise partiram da UNASUL, apesar de se tratar de uma frágil iniciativa que não apresentou resultados concretos.

De acordo com Cervo e Lessa (2014, p. 145), o cenário conturbado da América Latina de maneira geral decorria "da queda dos preços dos produtos primários, da queda das exportações e da maior oferta da manufaturados provindos da Ásia". Uma vez que o dinamismo do comércio exterior brasileiro registrado no governo Lula estava 
intimamente ligado ao dinamismo das exportações de manufaturados, tendo a América do Sul como um dos principais destinos, no governo Dilma havia a necessidade de reestruturação produtiva do setor manufatureiro, o que não foi feito (Cervo; Lessa, 2014). As consequências da ação errônea do governo Dilma referem-se a queda do ritmo de crescimento do PIB, queda das exportações de manufaturados, perda de parcela crescente do próprio mercado interno, queda do emprego, desindustrialização e reprimarização econômica - o único setor que se mantêm relativamente estável é o agronegócio.

Nesse cenário de crise econômica e necessidade de ampliação dos mercados, as negociações do Acordo de Associação oficialmente retomadas no governo Lula cresceram em importância. De acordo com Kegel e Amal:

A integração dos setores produtivos nacionais às redes de produção e de serviços europeia permitiria ganhos de produtividade e aumento da competitividade os quais, em conjunto com outras medidas de caráter doméstico, permitiriam eventualmente a reversão da tendência à reprimarização da economia brasileira. (Kegel; Amal 2015, p. 19).

Contudo, as negociações enfrentaram dificuldades devido à resistência da Argentina, ademais surgiram pressões de setores empresariais brasileiros para que se abandonasse a Tarifa Externa Comum (TEC) do Mercosul, e intentasse um acordo de livre-comércio Brasil-União Europeia. Essa alternativa foi recusada pelo governo brasileiro, no sentido de que, apesar de suas limitações, a TEC atuou como fator de coesão ao Mercosul e o Brasil não estava disposto a abandonar o projeto de liderança regional, ainda que tivessem diminuído os esforços (Saraiva; Gomes, 2016). Além disso, a União Europeia manteve a postura inflexível quanto à abertura do mercado agrícola, embora as reivindicações da abertura de determinados setores industrializados mercosulinos, de serviços e de compras públicas tenham se flexibilizado. Ademais, a Parceria Estratégica assinada com a União Europeia durante o governo Lula não rendeu frutos significativos durante o governo Dilma. Alguns diálogos bilaterais se desenvolveram, especificamente acerca do reforço do multilateralismo, direitos humanos e questões ambientais, mas não apresentaram resultados relevantes. 
Por fim, durante a segunda fase de negociações do Acordo de Associação não foram trocadas propostas entre os blocos, e em 2012 inicia-se um novo período de estagnação. O descontentamento econômico e a profunda cisão política no cenário doméstico brasileiro fez ascender ao poder forças políticas que levaram ao cabo o processo conturbado de impeachment da presidente Dilma em 2016, cuja legitimidade foi questionada por alguns setores da sociedade que o consideram um golpe parlamentar e jurídico travestido na alegação de crime de responsabilidade (Miranda, 2019). Michel Temer, então vice-presidente, assumiu à presidência interina do Brasil em maio de 2016.

\section{GOVERNO TEMER (2016-2018)}

Apesar do curto período de 2 anos, o governo de Michel Temer empenha-se em promover a ruptura com as linhas do governo anterior em uma mudança de rumos radical. Todavia, a burocracia especializada do Itamaraty conseguiu manter a política externa em uma linha de relativa continuidade, barrando mudanças excessivamente abruptas. Segundo Casarões (2016, p. 82), “as mudanças se balizam por um grande objetivo declarado: desconstruir o legado dos anos Lula/Dilma em política externa". Logo, José Serra foi nomeado como Ministro das Relações Exteriores e, em seu discurso de posse, afirmou que:

A diplomacia voltará a refletir de modo transparente e intransigente os
legítimos valores da sociedade brasileira e os interesses de sua economia, a
serviço do Brasil como um todo e não mais das conveniências e preferências
ideológicas de um partido político e seus aliados no exterior. A nossa política
externa será regida pelos valores do Estado e da nação, não do governo e
jamais de um partido (Brasil, 2016).

Nota-se no discurso de Serra que o Itamaraty, e governo interino de maneira geral, caracterizam-se pela crítica às gestões petistas anteriores, acusando-as de implementaram uma suposta ideologização e partidarização da política externa brasileira, principalmente em relação à integração regional. Nesse marco, as relações sul-americanas, que já enfrentavam dificuldades durante o governo Dilma, degradaramse rapidamente com a nova postura da diplomacia brasileira. Alguns países pronunciaram-se em favor da presidente Dilma no contexto do impeachment, e o Itamaraty lançou diversas notas à imprensa onde rejeitava enfaticamente as 
manifestações de Venezuela, Cuba, Bolívia, Nicarágua, El Salvador, da Aliança Bolivariana para os Povos de Nossa América (ALBA) e do então Secretário-Geral da UNASUL, Ernesto Samper (Casarões, 2016).

Nesse marco, a conduta brasileira tem impactos negativos para as estruturas de integração regional sul-americanas, visto a importância do país enquanto "centro gravitacional" da integração e a construção de sua atuação enquanto líder regional pautada pelos governos petistas anteriores. Todavia, a diplomacia brasileira reafirmou a importância estratégica do Mercosul e das relações com a Argentina, mas confere ênfase ao seu caráter comercial e à necessidade de renovar o bloco. Não obstante, em agosto de 2017, em uma reunião extraordinária do Mercosul convocada pelo Brasil, os países membros invocaram a cláusula democrática do bloco e aprovaram a suspensão da Venezuela (Miranda, 2019). Somado a isto, estagna-se o processo de admissão da Bolívia no bloco.

No campo econômico, o intuito da política externa do governo Temer foi a busca por investimentos, ancorada na construção da imagem do Brasil como um país defensor da ordem internacional vigente. Segundo Silva (2019, p. 34), "a ideia de um país 'responsável' economicamente substituiu a de um país 'pujante' e 'emergente'" e "a busca por tal renovação de credenciais substituiu a busca por uma revisão da ordem internacional". O governo de Michel Temer segue as diretrizes contidas no documento Uma ponte para o futuro, cujo objetivo principal é liberalização radical e abrangente da economia brasileira, simbolizada na proposta de adesão à Organização de Cooperação e Desenvolvimento Econômico (OCDE) (Menezes; Paiva, 2019).

Nesse contexto, os presidentes Michel Temer e Maurício Macri, da Argentina, encabeçaram a busca pelo Acordo de Associação com a União Europeia. Em maio de 2016, foi realizada a troca de ofertas do acordo, após 12 anos desde a primeira troca de propostas. De acordo com Menezes e Paiva (2019, p. 202):

No governo Temer, podemos afirmar que a motivação, para encabeçar de modo contundente o processo de negociação de acordos de livre-comércio, em especial o acordo entre Mercosul e a União Europeia, assim como a aproximação com a Aliança do Pacífico, vem da percepção e ou da narrativa de que o Brasil estaria isolando-se cada vez mais da tendência integracionista mundial.

O contexto da crise econômica, aliado à crise política e à insatisfação de setores 
produtivos brasileiros, além da tendência liberalizante do governo interino, promoveu reaproximação do Brasil com países desenvolvidos do Ocidente. Em síntese, o governo Temer mudou o tom da ação diplomática brasileira ao endurecer as críticas à países considerados aliados dos governos petistas, notadamente latino-americanos, e enunciou uma guinada em direção aos temas comerciais e à reaproximação com parceiros do "primeiro mundo", como Estados Unidos, Europa e Japão.

Em junho de 2018, Mercosul e União Europeia alcançaram entendimento sobre os pilares de diálogo político e de cooperação que compuseram o Acordo de Associação. Todavia, a conclusão das negociações de livre-comércio iria apenas se consumar no governo seguinte, de Jair Bolsonaro.

\section{GOVERNO BOLSONARO (2019 - atual)}

Se o governo de Michel Temer intentou promover ruptura com os governos petistas, o governo de Jair Bolsonaro assumiu a ruptura como meta principal. Bolsonaro apresentou-se não somente como antipetista, mas como antissistema. O posicionamento de extrema direita, com traços liberais na economia e conservador nos costumes, situou-o como novo polo político, determinado a desconstruir totalmente o legado da gestão petista (Casarões, 2019). Nesse marco, a política externa bolsonarista "persegue o desenvolvimento por meio da reconstrução da identidade internacional do Brasil" (Casarões, 2019, p. 235). Para isso, procura alinhar-se com países considerados democráticos e desenvolvidos.

O alinhamento automático e subordinado aos Estados Unidos têm sido o centro norteador da política externa brasileira. No âmbito regional, o alinhamento com os Estados Unidos estremeceu ainda mais as relações com os países da região, e minou o projeto de liderança regional brasileiro. Seguindo os posicionamentos do governo Temer, o atual governo inflamou as relações com a Venezuela, direcionando duras críticas ao regime de Maduro. Ao que tudo indica, a crise venezuelana se converteu em oportunidade para os Estados Unidos reestabelecerem a hegemonia no hemisfério e reanimar a Doutrina Monroe (Rodrigues, 2019).

No caso do Mercosul, mesmo antes da candidatura, Jair Bolsonaro já rejeitava o

bloco. Bolsonaro insistia que era necessário que o Brasil se livrasse das amarras 
institucionais do Mercosul e investisse em acordos comerciais bilaterais (Casarões, 2019). Setores empresariais compartilham da crítica, que se refere especificamente à Decisão CMC 32/00 responsável por estabelecer a TEC e a negociação conjunta de acordos comerciais com outros países ou blocos (Kegel; Amal, 2015). O ministro da Economia, Paulo Guedes, fez duras críticas ao Mercosul logo após a eleição de Bolsonaro, acusando-o de ser "totalmente ideológico" e afirmando que, dentro do plano econômico do novo governo, o Mercosul não seria prioridade.

Destarte, ao início do governo haviam poucas expectativas em relação ao aprofundamento do Mercosul. No entanto, a conclusão das negociações do Acordo de Associação Mercosul-UE em 28 de junho de 2019, apenas seis meses após o início do governo, renovou a importância do bloco para o Brasil. A conclusão do acordo foi comemorada pelo presidente Bolsonaro, que parabenizou o trabalho nas negociações de Ernesto Araújo, Tereza Cristina, a ministra da Agricultura, e Marcos Troyjo, Secretário Especial de Comércio Exterior e Assuntos Internacionais do Ministério da Economia (Mendonça, 2019). Em entrevista, Troyjo afirmou que o mérito da conclusão do acordo deve ser atribuído ao presidente Bolsonaro, por ter respaldado as políticas liberalizantes lideradas pelo Ministério da Economia. Nas palavras de Troyjo (2019):

\footnotetext{
Na minha opinião, o que foi decisivo pra a gente chegar nesse resultado chama-se presidente Jair Bolsonaro. Foi a determinação do presidente em fazer acordos com os quatro cantos do mundo; [ele] endossou as nossas políticas de maior inserção do Brasil na economia mundial, o fato da gente ter consolidado o Ministério da Economia nos permitiu trazer a política comercial para o coração da política econômica, que é algo que nunca aconteceu no Brasil também; temos uma sintonia perfeita com a parte da coordenação negociadora realizada pelo Ministério das Relações Exteriores, pelo chanceler Ernesto Araújo, pelo embaixador Pedro Miguel, o mesmo em relação ao Ministério da Agricultura.
}

Nesse sentido, a conclusão do acordo revela que o Mercosul continua sendo uma ferramenta importante na estratégia externa de seus países membros, notadamente do Brasil, embora no início do seu mandato, o presidente Bolsonaro tenha expressado que o bloco não seria prioridade (Frenkel, 2019). Além disso, o presidente Maurício Macri, da Argentina, também desempenhou um papel fundamental na conclusão do acordo. De acordo com Sanahuja e Rodríguez (2019), em um primeiro momento, a ascensão de Jair Bolsonaro indicava a desistência brasileira em liderar a negociações com a UE, que 
havia marcado as duas fases anteriores. Tal liderança teria sido assumida pela Argentina, que empregou intensa atividade diplomática com vistas ao fechamento do acordo. Contudo, a fala de Troyjo contradiz essa afirmação.

O relacionamento estratégico entre Brasil e Argentina tem sido, antes de tudo, o eixo sustentador do Mercosul. Em vista disso, as tensões entre o recém-eleito presidente Alberto Fernández, na Argentina, e o presidente Bolsonaro pode ter implicações para o Mercosul e para a consolidação do acordo com a União Europeia. Segundo o ex-ministro das relações internacionais do Brasil, Celso Amorim, o Acordo foi realizado em momento desfavorável ao Mercosul, dado à fragilidade nas relações entre Brasil e Argentina, permitindo à União Europeia maior poder barganha. Ademais, a aproximação entre os presidentes Trump e Bolsonaro incidiu na aceleração da conclusão do acordo pelos europeus (Carneiro, 2019). Nessa lógica, tudo indica que, uma vez ratificado pela União Europeia, o acordo poderá entrar em vigor para os países membros do Mercosul individualmente, à medida que cada um deles concluir seu processo de ratificação.

Há um longo caminho a ser percorrido até a efetiva implementação do acordo. Alguns analistas preveem um período de 2 a 5 anos para que o acordo entre em vigor. Por ora, o acordo está passando por uma revisão técnica e jurídica, e será realizada a sua tradução para os idiomas oficiais das partes. Depois, o acordo deverá ser assinado formalmente pelo Conselho da União Europeia e pelos países membros do Mercosul. Logo, o acordo passará pela aprovação do Parlamento Europeu, para depois ser ratificado por todos os países membros da UE. No caso do Brasil, o acordo será encaminhado para o Congresso Nacional, para a apreciação pela Câmara dos Deputados e pelo Senado Federal e, se aprovado, o Poder Executivo poderá ratificar o acordo.

Por sua vez, grupos de oposição ao acordo se manifestaram em defesa da estratégia autônoma de desenvolvimento regional. Cinco das principais associações sindicais brasileiras revelaram preocupação diante o tratado, justificando a fragilidade da indústria nacional dos setores automobilístico, autopeças, químico e fármaco, os quais perderiam espaço na participação do PIB brasileiro com a redução de tarifas. Segundo as elites econômicas da indústria, o acordo reforçaria a condição brasileira de 
fornecedor de commodities e importador de bens alto valor agregado. Somam-se a esse setor, as centrais sindicais, com diversas preocupações, dentre as quais o risco ao programa brasileiro de produção de genéricos, já que o acordo entre blocos prevê a proteção de patentes de fabricação de medicamentos. O tratado entre blocos agravaria o processo de enfraquecimento da indústria brasileira, que em 2018 registrou participação de apenas 11,3\% do PIB nacional (Dyniewicz, 2019).

À guisa de conclusão, é possível compreender o posicionamento da política externa brasileira frente ao acordo com a UE quando se elucida os respectivos contextos político-econômicos, domésticos e internacionais, e os posicionamentos políticoideológicos de cada presidente, visto a importância da diplomacia presidencial para a condução da política externa no Brasil. Nesse sentido, entende-se que o governo de Jair Bolsonaro promoveu mudanças no direcionamento da diplomacia brasileira no que se refere ao acordo, chegando de fato à sua conclusão.

\section{CONSIDERAÇÕES FINAIS}

Toda política externa, em alguma medida, constitui-se como uma tentativa de compatibilizar o quadro interno de um país com o contexto externo, ou as necessidades domésticas com as possibilidades presentes no cenário internacional. Entende-se que, a partir da análise das diretrizes e ações de política externa brasileira, é possível compreender as mudanças ocorridas no relacionamento do Brasil com o Mercosul - e com a integração regional de maneira geral - e com a União Europeia. Tais mudanças elucidam as razões do Acordo de Associação Mercosul-UE, cujas negociações iniciaramse há duas décadas, ser concluído no ano de 2019 e sob a política externa do governo Bolsonaro.

No governo Lula, a política externa brasileira caracterizou-se pela estratégia de inserção do Brasil como potência no cenário internacional a partir da consolidação da liderança brasileira na região, utilizando-se da integração regional como plataforma para a projeção internacional do país. Nesse cenário, as negociações do Acordo Mercosul-UE tiveram o seu período mais longo de estagnação após a troca de propostas insatisfatórias para ambas as partes em 2004, e a falha tentativa de retomar as negociações em 2010. Não obstante, em 2007 foi assinada a Parceria Estratégica 
Brasil-UE, que se configurou como um instrumento político a partir da percepção europeia de que o Brasil seria o 'líder natural' da América do Sul, o que poderia levar à uma evolução do acordo, que não se concretizou.

O governo Dilma, por sua vez, seguiu as mesmas diretrizes de política externa do governo anterior, com menor atividade e maiores limitações externas, devido ao perfil administrativo da presidente e à sua inábil diplomacia presidencial, além dos efeitos da crise econômica de 2008. Apesar das tentativas de retomar as negociações visto as pressões de setores produtivos brasileiros para maior abertura e liberalização econômica, os mesmos entraves de 2004 foram encontrados e a resistência da Argentina de Cristina Kirchner paralisou novamente as negociações.

Após o impeachment da presidente Dilma, Michel Temer assumiu à presidência com o objetivo declarado de desconstruir o legado das gestões petistas anteriores na política externa brasileira. Temer mudou o tom da ação diplomática brasileira ao endurecer as críticas à países considerados aliados dos governos petistas, notadamente latino-americanos, e enunciou uma guinada em direção à liberalização econômica e à busca por investimentos, a partir da aproximação com parceiros do "primeiro mundo", como Estados Unidos, Europa e Japão. A eleição de Maurício Macri, na Argentina, e a sua aliança com Michel Temer, tornou o acordo com a União Europeia prioridade máxima na agenda mercosulina. Destarte, em maio de 2016 foi realizada nova troca de ofertas do acordo entre Mercosul e UE e, em junho de 2018, os blocos alcançaram um entendimento sobre os pilares de diálogo político e cooperação que compõe o Acordo de Associação.

Em 28 de junho de 2019, concluiu-se a parte comercial do Acordo Mercosul-UE, já durante o governo de Jair Bolsonaro. A ascensão de Bolsonaro no Brasil representou a ruptura mais radical com a tradição de política externa brasileira desde os regimes militares. Sob o discurso inflamado antipetista e antissistema, o governo Bolsonaro, sob as diretrizes de Ernesto Araújo, no Ministério das Relações Exteriores, e Paulo Guedes, no Ministério da Economia, adotou uma postura messiânica em reação ao globalismo e à suposta corrosão da civilização ocidental. A partir de uma agenda econômica de liberalização econômica radical e de alinhamento aos países desenvolvidos do Ocidente, 
nomeadamente Estados Unidos e Europa, o governo brasileiro adotou uma postura proativa frente às negociações do acordo com a UE. Além disso, a sua conclusão renova a importância do Mercosul para o Brasil, como instrumental para a inserção econômica internacional.

A despeito dos possíveis benefícios e malefícios do Acordo de Associação MercosulUE, há ainda um longo percurso até a implementação efetiva do acordo. A ratificação do acordo pelos países europeus é especialmente problemática, visto as tensões diplomáticas do Brasil com a França e com a Alemanha, especialmente a respeito de questões ambientais e proteção dos direitos humanos.

Não obstante, as concessões feitas pelos países mercosulinos são indicativas de uma nova postura político-ideológica no Brasil, além de um cenário internacional e doméstico de crise econômica. Em conclusão, devido às possíveis dificuldades de ratificação do acordo, o governo Bolsonaro sinalizou que pretende implementá-lo com ou sem os outros países do Mercosul, o que contradiz a lógica de integração regional. Todavia, o Mercosul ganhou uma sobrevida importante com a conclusão do acordo.

\section{REFERÊNCIAS BIBLIOGRÁFICAS}

Brasil. (2019). Governo Federal. Acordo de Associação Mercosul-União Europeia. Disponível em: <http://www.mdic.gov.br/images/REPOSITORIO/secex/deint/cgne/2019_07_03__Resumo_Acordo_Mercosul_UE.pdf>. [Acesso em: 10 dez. 2019].

. (2019). Ministério das Relações Exteriores. Texto do Acordo Mercosul - União Europeia. Disponível em: <http://www.itamaraty.gov.br/pt-BR/notas-aimprensa/20626-texto-do-acordo-mercosul-uniao-europeia>. [Acesso em: 13 dez. 2019].

(2016). Ministério das Relações Exteriores. Discurso do ministro José Serra por ocasião da cerimônia de transmissão do cargo de ministro de estado das Relações Exteriores, Brasília. Disponível em: <http://www.itamaraty.gov.br/pt-BR/discursosartigos-e-entrevistas-categoria/ministro-das-relacoes-exteriores-discursos/14038discurso-do-ministro-jose-serra-por-ocasiao-da-cerimonia-de-transmissao-do-cargo-deministro-de-estado-das-relacoes-exteriores-brasilia-18-de-maio-de-2016>. [Acesso em: 15 dez. 2019].

Carneiro, J. (2019). UE fechou acordo 'com pressa' porque Mercosul está em situação frágil, diz Celso Amorim. BBC News Brasil. Disponível em: <https://www.bbc.com/portuguese/brasil-48808097>. [Acesso em: 25 de fev. 2020]. 
Casarões, G. (2019) "Eleições, política externa e os desafios do novo governo brasileiro", in: Serbin, A.; Pedroso, C. S.; Pont, A. S. Pensamiento Próprio. América Latina y el Caribe en un mundo en transición: actores extrarregionales y estrategias latinoamericanas. $V$. 24 , p. 231-274.

(2016) "A política externa interina e os riscos à integração regional". Revista Conjuntura Austral, 7(37), p. 81-93.

Cervo, A.; Lessa, A. (2014). "O declínio: inserção internacional do Brasil (2011-2014)". Revista Brasileira de Política Internacional, 57(2), p. 133-151.

Cornetet, J. (2014). "A Política Externa de Dilma Rousseff: Contenção na Continuidade”. Revista Conjuntura Austral, 5(24), p. 111-150.

Dyniewicz, L. (2019). "Estagnada, Indústria tem a menor fatia do PIB desde o final dos anos 40". 0 Estado de S. Paulo. Disponível em: $<$ https://economia.estadao.com.br/noticias/geral,estagnada-industria-tem-a-menorfatia-do-pib-desde-o-final-dos-anos-40,70002783202>. [Acesso em: 28 fev. 2020].

European Comission. (2019). EU-Mercosur trade agreement: The Agreement in Principle and its texts. Disponível em: <https://trade.ec.europa.eu/doclib/press/index.cfm?id=2048>. [Acesso em: $13 \mathrm{dez}$. 2019].

Frenkel, A. (2019). Los perdedores de siempre: Apuntes sobre el acuerdo entre la Unión Europea y el Mercosur. Nueva Sociedad, Opinión. Disponível em: $<$ https://nuso.org/articulo/ue-mercosur-europa-ganadores-perdedores-integracion/>. [Acesso em: 13 dez. 2019].

Hoffmann, A. (2009). "EU-Mercosur Relations after the EU-Brazilian Strategic Partnership", in: Martins, E. C. R.; Saraiva, M. G. (Orgs.). Brasil, União Europeia, América do Sul: anos 2010-2020. Rio de Janeiro: Fundação Konrad Adenauer.

Kegel, P.; Amal, M. (2015). "A política comercial brasileira entre a crise do Mercosul e as negociações com a União Europeia”. Boletim Meridiano 47, 16(152), p. 13-20.

Mariano, K. (2019). Algumas reflexões sobre o Acordo Mercosul-União Europeia. Observatório de Regionalismo. Disponível em: <http://observatorio.repri.org/artigos/algumas-reflexoes-sobre-o-acordo-mercosuluniao-europeia/>. [Acesso em: 10 dez. 2019.]

Miranda, S. (2019). “"Nova política externa brasileira” de Temer para a América do Sul'. Revista Conjuntura Austral, 10(51), p. 126-138.

Mendonça, H. (2019). Mercosul e União Europeia selam esperado acordo após 20 anos de negociações. El País, São Paulo. Disponível em: <https://brasil.elpais.com/brasil/2019/06/28/economia/1561741745_016799.html>. [Acesso em: 16 dez. 2019]. 
Menezes, R.; Paiva, S. (2019). 'Agora vai? As negociações do Acordo Mercosul-União Europeia no contexto da nova onda de liberalização radical da economia brasileira", in: Esposito Neto, T.; Almeida Prado, H. S. (Orgs.). União Europeia: visões brasileiras. 1. ed. Curitiba: Appris.

Pennaforte, C.; Ribeiro, G.; Bones, N. (2018). "Acordo Mercosul-União Europeia: entre o discurso e a realidade. Impactos e Perspectivas". Revista Conjuntura Austral, 9(46), p. 521.

Ricupero, R. (2017). "Parte XI: O apogeu e a crise da Nova República (1995-2010)", in: Ricupero, R., A diplomacia na construção do Brasil: 1750-2016. Rio de Janeiro: Versal, p. 639-698.

Rodrigues, G. (2019). ¿El Trump del trópico? Política exterior de ultraderecha en Brasil. Análisis Carolina 06/2019/ES. Madrid: Fundación Carolina.

Sanahuja, J.; Rodríguez, J. (2019). Veinte años de negociaciones Unión-EuropeaMercosur: Del interregionalismo a la crisis de la globalización. Documentos de Trabajo $n^{\circ} 13$ (2a época). Madrid: Fundación Carolina.

Saraiva, M.; Gomes, Z. (2016). "Os limites da Política Externa de Dilma Rousseff para a América do Sul”. Relaciones Internacionales, n. 50, p. 81-97.

(2009). "A diplomacia brasileira e as visões sobre a inserção externa do Brasil: institucionalistas pragmáticos $\mathrm{x}$ autonomistas". Mural Internacional, 1(1).

(2009). "O Brasil entre a União Europeia e a América do Sul entre continuidades e mudanças nos governos de Cardoso e Lula: limites para uma relação triangular", in: Martins, E. C. R.; Saraiva, M. G. (Orgs.). Brasil, União Europeia, América do Sul: anos 2010-2020. Rio de Janeiro: Fundação Konrad Adenauer.

Silva, Á. (2019). “A política externa do Governo Michel Temer (2016-2018): mudanças para a legitimidade? Um teste da teoria de Charles Hermann". Revista Conjuntura Austral, 10(49), p. 23-41.

Vigevani, T. (2008). "O papel da integração regional para o Brasil: universalismo, soberania e percepção das elites". Revista Brasileira de Política Internacional, 51(1), p. 5-27.

Xadrez Verbal Podcast \#ESPECIAL - Acordo MERCOSUL-União Europeia - Parte 2. (2019). Entrevistador: Filipe Figueiredo. Entrevistados: Vivian Almeida, Rafael Mafra, Andrés Malamud, Gustavo Rebelo, Marcos Troyjo, João Romero e Santiago Rodríguez Rey. Central3, 15 jul. Podcast. Disponível em: <https://xadrezverbal.com/2019/07/15/xadrez-verbal-podcast-especial-acordomercosul-ue-parte-2/>. [Acesso em: 16 dez. 2019].

Zelicovich, J. (2019). El Acuerdo Mercosur-Unión Europea en su recta final. Análisis Carolina. Madrid: Fundación Carolina, julio 2019. Disponível em: 
<https://www.fundacioncarolina.es/wp-content/uploads/2019/07/AC-13.pdf>. [Acesso em: 13 dez. 2019]. 